\title{
Induced Rice Resistance to Blast Varies as a Function of Magnaporthe grisea Avirulence Genes
}

\author{
N. Yasuda, Senior Researcher, Rice Disease Resistance Research Team, National Agricultural Research Center, Tsu- \\ kuba 305-8666, Japan; M. T. Noguchi, Researcher, Environmental Biofunction Division, National Institute for Agro- \\ Environmental Sciences, Tsukuba, 305-8604, Japan; and Y. Fujita, Team Leader, Rice Disease Resistance Research \\ Team, National Agricultural Research Center, Tsukuba 305-8666, Japan
}

\begin{abstract}
Yasuda, N., Noguchi, M. T., and Fujita, Y. 2008. Induced rice resistance to blast varies as a function of Magnaporthe grisea avirulence genes. Plant Dis. 92:1144-1149.

Incompatibility reactions between rice and the blast fungus Magnaporthe grisea produce various degrees of lesions, from large brown flecks to small, nearly invisible lesions. We previously identified four avirulence genes (AvrPia, AvrPii, AvrPit, and Avr-Hattan3) in M. grisea isolates by genetic analysis of progeny from crosses between isolates with differing pathogenicity. Using progeny known to contain a specific avirulence gene, we demonstrated that the type of resistance lesion produced in rice by an avirulent isolate and the degree of leaf blast suppression by preinoculation with that isolate were determined by the combination of avirulence and resistance genes in the isolate and the cultivar. The degree of leaf blast suppression by preinoculation with an avirulent isolate increased with larger resistance lesions. When two genes were involved in an isolate's avirulence, lesions appeared that resembled those expected for the gene that produced the smaller lesion. The degree of leaf blast suppression by the isolate with two avirulence genes was comparable with that induced by the isolate with the avirulence gene that produced the smaller effect. The ability of specific resistance gene combinations that effectively suppress blast disease is discussed for each avirulence gene.
\end{abstract}

Additional keywords: gene-for-gene hypothesis, Pyricularia grisea

Rice blast caused by Magnaporthe grisea (T.T. Hebert) M.E. Barr (4) (anamorph Pyricularia grisea (Cooke) Sacc.; 28 ) is one of the most economically devastating diseases of rice worldwide. The extensive use of blast-resistant rice cultivars has led to the emergence of new blast fungus races that are virulent in resistant cultivars, and subsequent breakdown of cultivar resistance to the disease. One of the strategies for developing rice cultivars with durable blast resistance is to breed multilines-mixtures of near-isogenic lines (NILs) that contain different genes for resistance to blast. In Japan, the multiline method has been adopted to control blast $(2,19)$. In multilines, disease epidemics are reduced by (i) spore deposition on resistant plants, (ii) spore dilution because of the greater distance between plants of the same genotype, and (iii) induction of

Corresponding author: N. Yasuda

E-mail: yasuda@affrc.go.jp

Accepted for publication 11 April 2008.

doi:10.1094/PDIS-92-8-1144

(C) 2008 The American Phytopathological Society defense responses in susceptible plants by avirulent isolates on specific host genotypes $(3,20)$. Therefore, to effectively control blast using multilines, it is important to assess the efficacy of disease reduction by avirulent isolates.

Avirulent isolates of the rice blast fungus were previously reported to suppress infection by virulent isolates of the same fungus by inducing resistance $(3,10,23,26)$. Fujita et al. (8) examined the ability of various avirulent isolates to reduce blast by preinoculation, and found that the reduction of lesion number of virulent isolate varied with the avirulent isolates used to preinoculate the rice. They also showed that the types of lesions created by the avirulent isolates in resistant cultivars determined the degree of leaf blast suppression. It is not known what controlled the types of lesions created by the avirulent isolates.

The avirulence or virulence of the blast fungus in a certain rice cultivar is known to follow the gene-for-gene hypothesis $(7,30)$, in which the pathogen carries a gene for avirulence that corresponds to a resistance gene in the host. The results of these studies led us to hypothesize that the efficacy of blast disease reduction in rice by an avirulent isolate of the blast fungus would be determined by the combination of avirulence and resistance genes.

We have previously identified four avirulence (avr) genes (AvrPia, AvrPii, AvrPit, and Avr-Hattan3) in our laboratory isolates of $M$. grisea and four resistance genes (Pia, Pii, Pit, and Pi-Hattan3) in Japanese rice cultivars that correspond to these four $a v r$ genes $(35,36)$. In the present study, we used combinations of blast isolates and rice cultivars containing these genes to investigate the types of lesion produced by the avirulent isolates. Moreover, we compared the ability of the avirulent isolates to suppress blast disease after preinoculation of the host.

\section{MATERIALS AND METHODS}

$M$. grisea isolates and plant materials. Eleven isolates of $M$. grisea were used in this study. Their avirulence or virulence with respect to three cultivars (Aichiasahi, Miyamanishiki, and K59), their avr genotypes, the sources of the isolates, and the relevant references to the research literature are listed in Table 1. Isolates AI33 and AI3 are progeny of a cross between isolates Y93-165g-1 and Y93-164a-1. AI33 was found to contain both AvrPia and AvrPii and to express an avirulent phenotype, whereas AI3 contained neither gene and was virulent (35). Isolates A53 and A4 are the progeny of a cross between isolates Y90-71 and 3514-R-2. A53 contained both Avr-Hattan 3 and AvrPit and, thus, exhibited an avirulent phenotype, whereas A4 contained neither gene and was virulent (36).

To produce the inoculum, $M$. grisea isolates were grown on oatmeal agar (1 liter of distilled water, $15 \mathrm{~g}$ of agar, $20 \mathrm{~g}$ of sucrose, and $50 \mathrm{~g}$ of ground oatmeal) at $26^{\circ} \mathrm{C}$ for 11 to 12 days, and then the aerial mycelia were gently washed off using a water-soaked paintbrush. The mycelia were then kept at $21^{\circ} \mathrm{C}$ for 3 to 4 days under continuous illumination with fluorescent light $(18 \mathrm{~W})$ to induce sporulation. To create a conidial suspension, the mycelia were scraped from the growth medium and flooded with water containing $0.01 \%$ Tween 20. The conidial suspension was 
then filtered through a gauze mesh and adjusted to between $1 \times 10^{5}$ and $2 \times 10^{5}$ conidia/ml by using a hemacytometer.

The rice cultivars used in this study and their known blast resistance genes are listed in Table 2. The resistance gene that corresponds to the avr gene Avr-Hattan3 was identified as a single dominant gene (36). This resistance gene was named $\mathrm{Pi}$ Hattan3.

Estimation of lesion-based types of resistance. Six plants of each rice cultivar were prepared for the inoculation of each blast isolate at one time and the inoculation experiments were repeated independently. Seed were sown in 15-by-5-by-10$\mathrm{cm}$ plastic trays (each tray had five rows of six seeds and each row was a different cultivar). Plants were grown in a greenhouse at 20 to $30^{\circ} \mathrm{C}$ under ambient lighting conditions.

Rice seedlings in each tray were inoculated at the five-leaf stage by spraying with $30 \mathrm{ml}$ of the conidial suspension from a single blast isolate. The inoculated seedlings were immediately placed in a dark chamber with a moisture-saturated atmosphere at $25^{\circ} \mathrm{C}$ for $18 \mathrm{~h}$ and then transferred to a greenhouse at 20 to $28^{\circ} \mathrm{C}$ under ambient lighting conditions. About 7 days after inoculation, we assessed the lesion types that developed. The most severe type of lesion produced on the youngest leaves of the cultivar that were present at the time of inoculation was used to rate the lesion type caused by the isolate. Lesion types of resistance were evaluated according to the Abumiya standard (1). However, we saw another lesion type, which is similar to what Kiyosawa called halo lesion (15). Therefore, we describe this lesion type as halo lesion in this report.

Quantification of the degree of leaf blast suppression by pre-inoculation with an avirulent isolate. Twenty seeds of each cultivar were sown in a 15-by-5-by$10-\mathrm{cm}$ plastic tray. Plants were grown in a greenhouse at 20 to $30^{\circ} \mathrm{C}$ under ambient lighting conditions for 4 to 5 weeks. We then selected seedlings at the six-leaf stage once the youngest leaf had completely expanded, and discarded the other seedlings. The selected seedlings in each tray were inoculated by spraying $30 \mathrm{ml}$ of conidial suspension from an avirulent isolate $\left(1 \times 10^{5}\right.$ conidia/ml in distilled water containing $0.02 \%$ Tween 20). Control seedlings were preinoculated with $30 \mathrm{ml}$ of distilled water containing $0.02 \%$ Tween 20. The preinoculated seedlings were immediately placed in a dark chamber with a moisture-saturated atmosphere at $25^{\circ} \mathrm{C}$ for $18 \mathrm{~h}$, and then were transferred to a greenhouse at 20 to $28^{\circ} \mathrm{C}$ under ambient lighting conditions. At $48 \mathrm{~h}$ after the preinoculation, the rice seedlings were inoculated again with $30 \mathrm{ml}$ of conidia suspension (1 $\times 10^{5}$ conidia $/ \mathrm{ml}$ in distilled water containing $0.02 \%$ Tween 20 ) of one of the two virulent isolates: AI3 or A4. The inoculated seedlings were immediately placed in a dark chamber with a moisture-saturated atmosphere at $25^{\circ} \mathrm{C}$ for $18 \mathrm{~h}$ and then transferred to a greenhouse at 20 to $28^{\circ} \mathrm{C}$ under ambient lighting conditions. Seven days after the inoculation, the total numbers of sporulating lesions on the fifth and sixth leaf blades were counted. To estimate the relative degree of leaf blast suppression induced by each avirulent isolate, we calculated a lesion index as follows: lesion index $(\%)=\left(n_{\mathrm{P}} / n_{\mathrm{C}}\right) \times$ $100 \%$, where $n_{\mathrm{P}}$ is the number of sporulating lesions caused by the virulent isolate after preinoculation with the avirulent isolate and $n_{\mathrm{C}}$ is the number of sporulating lesions caused by the virulent isolate in the control seedlings. Experiments were done using 10 to 15 seedlings for one avirulent isolate at one time. The experiments were repeated seven times independently.

Statistical analysis. The mean lesion indices for preinoculation treatments with the avirulent isolates were analyzed using one-way analysis of variance (ANOVA). When a significant difference was detected

Table 2. Rice cultivars used in this study, their known blast resistance genes, and literature citations for each cultivar

\begin{tabular}{lll}
\hline Cultivar & Resistance genes & Reference \\
\hline Aichiasahi & Pia & 13 \\
Miyamanishiki & Pia, Pii & 32 \\
K59 & Pit, Pi-Hattanz & $15,17,36$ \\
Yamato 3 & Pia & 33 \\
Kiyonishiki & Pia & 18 \\
Kuzuryu & $P i a$ & Y. Fujita, unpublished \\
Yukinosei & Pia & 9 \\
Hourei & $P i i$ & 25 \\
Hokuriku 12 & Pii & 16 \\
Gohyakumangoku & Pii & 6 \\
Suehiromochi & $P i i$ & 33 \\
Ishikarishiroke & Pii & 34 \\
Fujisaka 5 & Pii & 34 \\
Megumimochi & Pia, Pii & 21 \\
Mineasahi & $P i a$, Pii & 24 \\
Takanenishiki & Pia, Pii & 29,32 \\
\hline
\end{tabular}

${ }^{\mathrm{z}}$ The resistance gene that corresponds to Avr-Hattan3 was shown to be Pi-Hattan3 in the present study.

Table 1. Magnaporthe grisea isolates used in this study, their avirulence or virulence with respect to three rice cultivars (Aichiasahi, Miyamanishiki, and K59), the sources of the isolates, and literature citations (Ref.) for each isolate ${ }^{x}$

\begin{tabular}{|c|c|c|c|c|c|c|c|c|c|}
\hline \multirow[b]{2}{*}{ Isolates } & \multirow[b]{2}{*}{ Race no. ${ }^{\mathrm{z}}$} & \multicolumn{3}{|c|}{$\begin{array}{l}\text { Genes that control } \\
\text { avirulence }\end{array}$} & \multicolumn{3}{|c|}{$\begin{array}{l}\text { Avirulence or } \\
\text { virulence }\end{array}$} & \multirow[b]{2}{*}{ Source } & \multirow[b]{2}{*}{ Ref. } \\
\hline & & Aich & Miya & K59 & Aich & Miya & K59 & & \\
\hline TH68-140 & 035.1 & AvrPia & AvrPia & AvrPit & A & A & A & Japan & 32 \\
\hline Ken54-20 & 003.0 & $\ldots$ & AvrPii & AvrPit & $\mathrm{V}$ & A & A & Japan & 15 \\
\hline Y93-165g-1 & 134.4 & AvrPia & AvrPia & $\ldots$ & A & A & $\mathrm{V}$ & China & 35 \\
\hline Y93-164a-1 & 132.4 & $\ldots$ & $A v r P i i$ & $\ldots$ & $\mathrm{V}$ & A & $\mathrm{V}$ & China & 35 \\
\hline Y90-71 & 102.0 & $\ldots$ & $\ldots$ & Avr-Hattan 3 & $\mathrm{~V}$ & $\mathrm{~V}$ & A & China & 36 \\
\hline 3514-R-2 & 136.0 & $\ldots$ & $\ldots$ & AvrPit & $\mathrm{V}$ & $\mathrm{V}$ & A & Laboratory isolate & 36 \\
\hline AI33 & 130.4 & AvrPia & AvrPia, & & & & & Progeny isolate from the cross between & \\
\hline & & & AvrPii & $\ldots$ & A & A & V & Y93-165g-1 and Y93-164a-1 & 35 \\
\hline $\mathrm{AI} 3$ & 136.4 & $\cdots$ & $\ldots$ & $\ldots$ & $\mathrm{V}$ & $\mathrm{V}$ & V & $\begin{array}{l}\text { Progeny isolate from the cross between } \\
\text { Y93-165g-1 and Y93-164a-1 }\end{array}$ & 35 \\
\hline A53 & 102.0 & $\ldots$ & $\ldots$ & $\begin{array}{l}\text { AvrPit, } \\
\text { Avr-Hattan3 }\end{array}$ & $\mathrm{V}$ & $\mathrm{V}$ & A & $\begin{array}{l}\text { Progeny isolate from the cross between } \\
\text { Y90-71 and 3514-R-2 }\end{array}$ & 36 \\
\hline A4 & 136.4 & $\ldots$ & $\ldots$ & $\ldots \square$ & $\mathrm{V}$ & V & V & $\begin{array}{l}\text { Progeny isolate from the cross between } \\
\text { Y90-71 and 3514-R-2 }\end{array}$ & 36 \\
\hline
\end{tabular}

${ }^{\mathrm{x}}$ Known resistance genes of rice cvs. Aichiasahi (Aich), Miyamanishiki (Miya), and K59are Pia, Pia+Pii, and Pit+Pi-Hattan3, respectively.

${ }^{\mathrm{y}} \mathrm{A}$ and $\mathrm{V}=$ avirulent and virulent, respectively.

${ }^{\mathrm{z}}$ Race number of the isolate was estimated according to the differential varieties established by Kiyosawa (17). 
$(P<0.05)$ among treatments, the means of the different treatments were compared using the Tukey-Kramer method.

\section{RESULTS}

Lesion types depended on the combination of resistance and $a v r$ genes. We observed lesion types in 27 combinations of rice cultivars after inoculation with eight blast isolates (Table 3). We saw four types of response, including no formation of visible lesions ( 0 lesions; Fig. 1C, right), minute brown flecks (b lesions; Fig. $1 \mathrm{~A}$ and $\mathrm{D}$ ), large brown flecks (B lesions;
Fig. 1B), and halo lesions (H lesions; Fig. $1 \mathrm{C}$, left and middle).

The rice $\mathrm{cv}$. Aichiasahi, which contained resistance gene Pia (13), was inoculated with one of two avirulent isolates (TH68140 or Y93-165g-1), all of which are known to contain the avr gene AvrPia

Table 3. Resistance lesion types on rice cultivars inoculated with Magnaporthe grisea isolates

\begin{tabular}{|c|c|c|c|c|c|c|c|}
\hline \multirow[b]{3}{*}{ Isolates } & \multirow[b]{3}{*}{ Avirulence genes } & \multicolumn{6}{|c|}{ Cultivars and resistance genes $^{z}$} \\
\hline & & \multirow{2}{*}{$\frac{\text { Aichiasahi }}{\text { Pia }}$} & \multirow{2}{*}{$\begin{array}{c}\text { Miyamanishiki } \\
\text { Pia, Pii }\end{array}$} & \multirow{2}{*}{$\begin{array}{c}\text { K59 } \\
\text { Pit, Pi-Hattan3 }\end{array}$} & \multirow{2}{*}{$\begin{array}{c}\text { Yamato } 3 \\
\text { Kiyonishiki } \\
\text { Kuzuryu } \\
\text { Yukinosei } \\
\text { Pia }\end{array}$} & \multirow[t]{2}{*}{$\begin{array}{c}\text { Hourei } \\
\text { Hokuriku } 12 \\
\text { Gohyakumangoku } \\
\text { Suehiromochi } \\
\text { Ishikarishiroke } \\
\text { Fujisaka 5 } \\
P i i\end{array}$} & \multirow{2}{*}{$\begin{array}{c}\begin{array}{c}\text { Megumimochi } \\
\text { Mineasahi } \\
\text { Takanenishiki }\end{array} \\
\text { Pia, Pii }\end{array}$} \\
\hline & & & & & & & \\
\hline TH68-140 & AvrPia, AvrPit & $\mathrm{b}$ & $\mathrm{b}$ & $\ldots$ & $\ldots$ & $\ldots$ & $\ldots$ \\
\hline Ken54-20 & AvrPii, AvrPit & $\ldots$ & $\mathrm{B}$ & $\mathrm{H}$ & $\ldots$ & $\ldots$ & $\ldots$ \\
\hline Y93-165g-1 & AvrPia & $\mathrm{b}$ & $\mathrm{b}$ & $\ldots$ & $\mathrm{b}$ & $\ldots$ & $\mathrm{b}$ \\
\hline Y93-164a-1 & AvrPii & $\ldots$ & B & $\ldots$ & $\ldots$ & $\mathrm{B}$ & $\mathrm{B}$ \\
\hline Y90-71 & Avr-Hattan3 & $\ldots$ & $\ldots$ & 0 & $\ldots$ & $\ldots$ & $\ldots$ \\
\hline $3514-\mathrm{R}-2$ & AvrPit & $\ldots$ & $\ldots$ & $\mathrm{H}$ & $\ldots$ & $\ldots$ & $\ldots$ \\
\hline $\mathrm{AI} 33$ & AvrPia, AvrPii & $\ldots$ & $\mathrm{b}$ & $\ldots$ & $\ldots$ & $\ldots$ & $\ldots$ \\
\hline A53 & AvrPit, Avr-Hattan3 & $\ldots$ & $\ldots$ & 0 & $\ldots$ & $\ldots$ & $\ldots$ \\
\hline
\end{tabular}

${ }^{\mathrm{z}}$ Lesion types were observed 7 days after inoculation. The most severe lesion produced on the fifth leaves of the host was used to rate the lesion type caused by the isolate. Lesion types of resistance were evaluated according to the description of Abumiya (1) and Kiyosawa (15) (see Materials and Methods). The lesion types are described as follows: b, minute brown flecks; B, large brown flecks; $\mathrm{H}$, lesions with a large brown halo; 0 , no visible lesion; and ... means that the inoculation test was not performed.

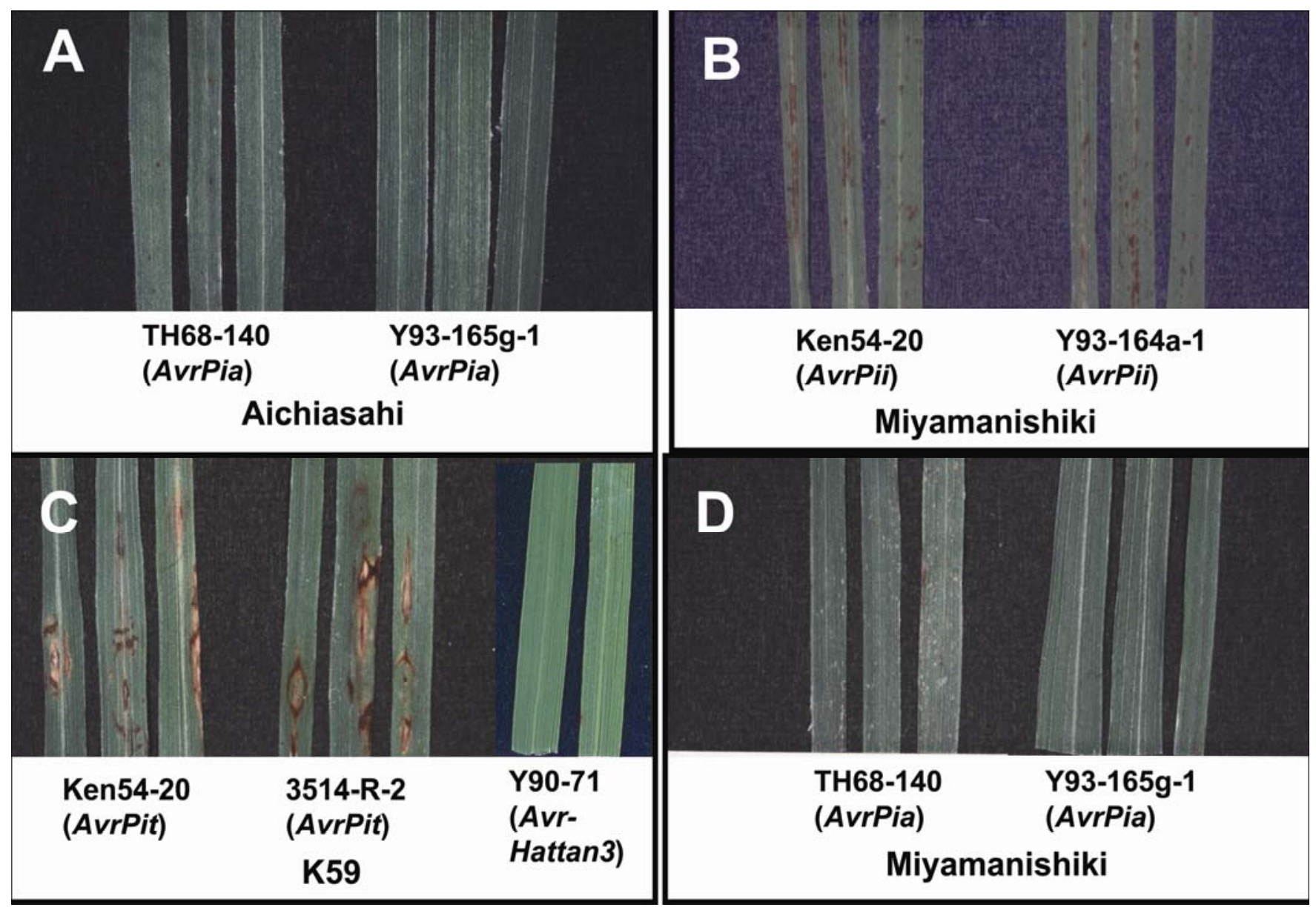

Fig. 1. Types of resistance lesions observed in rice cultivar-blast isolate combinations. A, Aichiasahi, B and D, Miyamanishiki, and C, K59 were inoculated with the indicated blast isolates. The avirulence genes of the respective blast isolates are listed in parentheses. 
(32,35), and all caused minute brown flecks to develop on Aichiasahi (Fig. 1A). All lesions observed on Miyamanishiki (with resistance gene Pia) in response to blast isolates TH68-140 and Y93-165g-1 (all with AvrPia) were minute brown flecks (Fig. 1D) similar to the lesions on Aichiasahi, which also contains Pia (Fig. 1A). Cvs. Yamato 3, Kiyonishiki, Kuzuryu, and Yukinosei, which are also known to contain Pia, were inoculated with Y93$165 \mathrm{~g}-1$ and developed minute brown flecks (Table 3). Isolates containing AvrPia all produced minute brown flecks on cultivars that carried the Pia resistance genes.

Cvs. Hourei, Hokuriku 12, Gohyakumangoku, Suehiromochi, Ishikarishiroke, and Fujisaka 5, all known to contain Pii, developed large brown flecks after inoculation with Y93-164a-1 (with AvrPii; Table 3 ). These lesions were similar to each other, although the size of the brown flecks varied slightly among the cultivars.

However, the lesion types produced by certain rice cultivars in response to different blast isolates were different occasionally. For example, Miyamanishiki developed large brown flecks in response to blast isolates Ken54-20 and Y93-164a-1 (Fig. 1B), whereas TH68-140 and Y93$165 \mathrm{~g}-1$ produced minute brown flecks (Fig. 1D). This variation is reasonable because Miyamanishiki contains both Pia and Pii (32). The resistance gene Pii in Miyamanishiki is effective against blast isolates Ken54-20 and Y93-164a-1, which contain AvrPii, whereas resistance gene $P i a$ is effective against TH68-140 and Y93-165g-1, which contain AvrPia. Three other cultivars (Megumimochi, Mineasahi, and Takanenishiki) confirmed that the lesion type is determined by whichever resistance gene is effective against a particular isolate. These cultivars are known to contain both Pia and Pii; thus, all three cultivars produced minute brown flecks when inoculated with Y93-165g-1, versus large brown flecks when inoculated with Y93-164a-1 (Table 3).

In addition, these blast isolates often contain several $a v r$ genes. For example, Ken54-20 contains both AvrPii and AvrPit (15). Thus, Miyamanishiki (Pia and Pii) produces large brown flecks in response to Ken54-20, whereas K59 (Pit) produces large brown lesions with haloes (Fig. 1B and $\mathrm{C}$ ).

Type of resistance lesion triggered by the presence of two avr genes. To determine the type of resistance lesion that develops when two avr genes trigger resistance in a rice cultivar, we used blast isolate AI33, which contains two avr genes. This isolate is a progeny from the cross between Y93-165g-1 and Y93-164a-1 and has been shown to contain both AvrPia and AvrPii (35). The lesion response of Miyamanishiki, which contains both Pia and Pii, to AI33 was to produce minute brown flecks, which is similar to its reaction to
Y93-165g-1 (Fig. 2). The blast isolate A53, which is the progeny of a cross between 3514-R-2 and Y90-71, was shown to contain both AvrPit and Avr-Hattan3 (36). This isolate caused no visible lesions on $\mathrm{K} 59$, which contains resistance genes to both $a v r$ genes, with results similar to those produced by inoculation with Y90-71 (Fig. 3). Thus, the types of resistance lesions triggered by the two avr genes resembled those caused by one or the other of the two avr genes.

Assessment of leaf blast suppression by preinoculation with an avirulent iso-

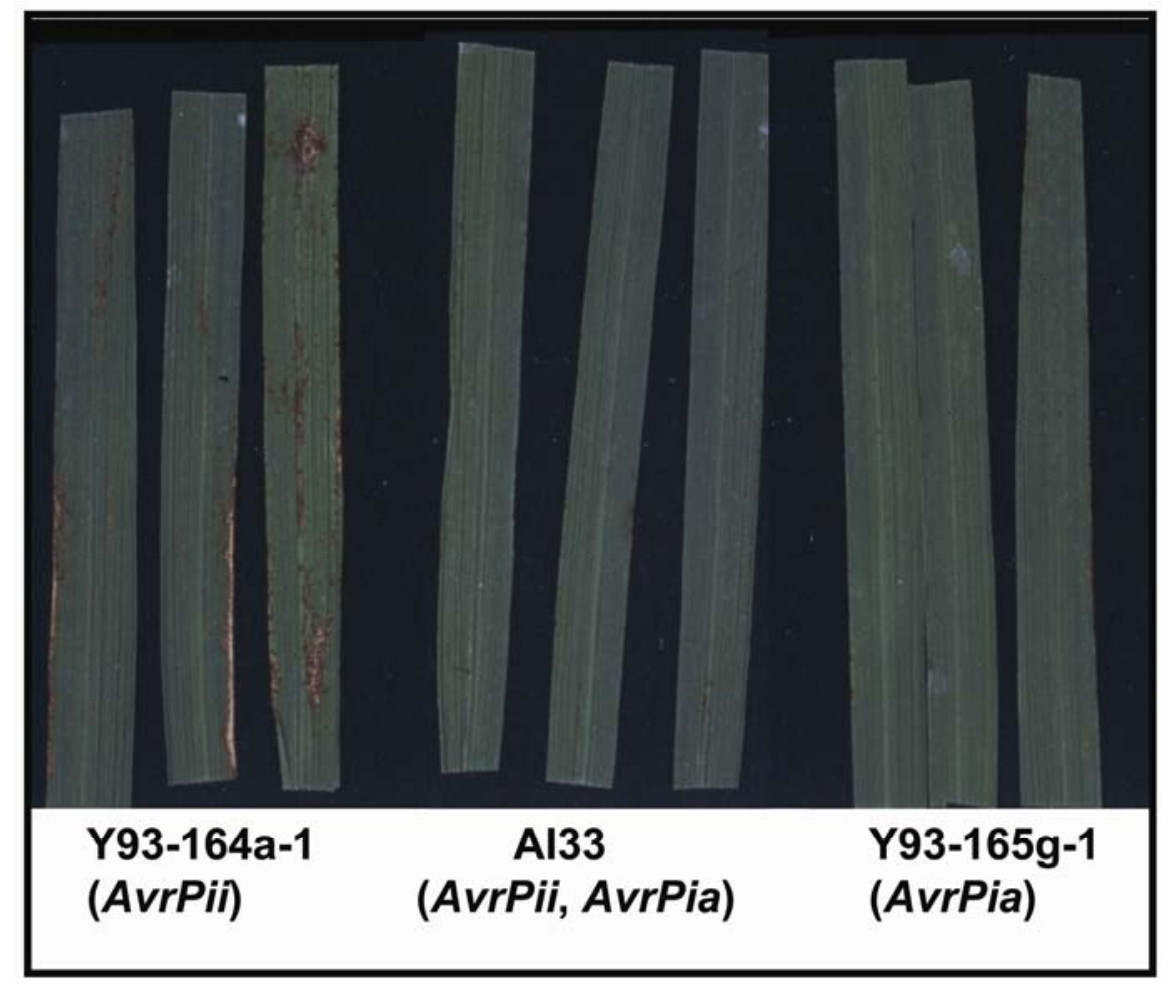

Fig. 2. Lesion types produced on Miyamanishiki in response to inoculation with three blast isolates (indicated below the leaves). The avirulence genes of the respective blast isolates are shown in parentheses.

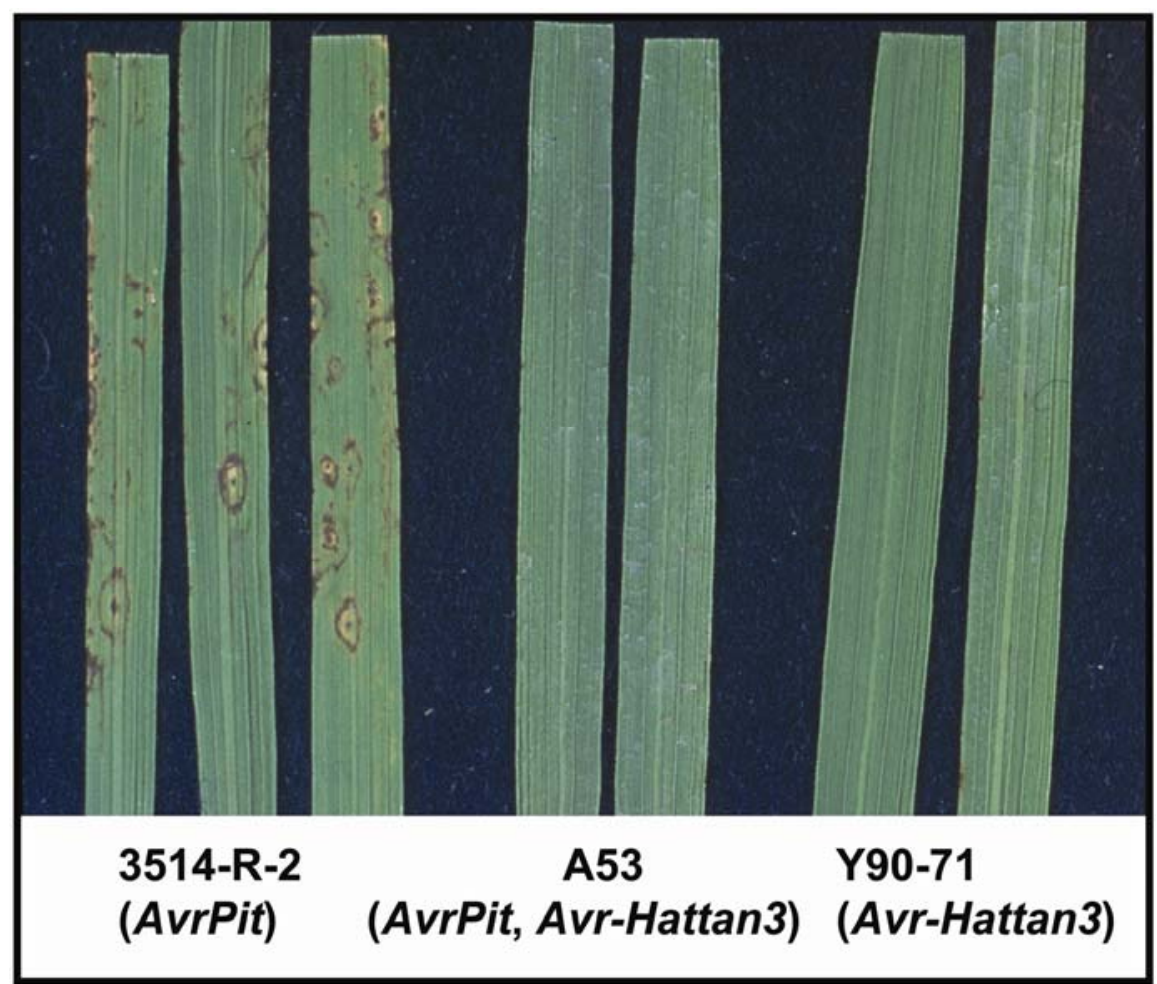

Fig. 3. Lesion types produced on K59 in response to inoculation with three blast isolates (indicated below the leaves). The avirulence genes of the respective blast isolates are shown in parentheses. 
late. We compared the lesion indices among treatments for Miyamanishiki and K59 (Table 4). Average number of lesions per plant caused by virulent isolates without preinoculation was $32.7 \pm 14.8$ (mean \pm standard deviation) on Miyamanishiki, and $26.6 \pm 28.8$ on K59. When Y93-164a-1 (with AvrPii) was used to preinoculate Miyamanishiki, the lesions caused by virulent isolate AI3 were suppressed to about 9\% compared with the control, which was not preinoculated with an avirulent isolate. When Y93-165g-1 (with AvrPia) was used as the preinoculum, lesions on Miyamanishiki caused by the virulent isolate were suppressed to about $26 \%$ of the control value. The lesion index for Y93-164a-1 (with AvrPii) was significantly lower than that for Y93-165g-1 (about 9 versus 26\%, respectively). In contrast, when avirulent isolate AI33 (with both AvrPia and AvrPii) was used as the preinoculum, the number of lesions was reduced to about $34 \%$. Similar results were obtained when K59 (with Pit and Pi-Hattan3) was inoculated (Table 4). When 3514-R-2 (with AvrPit) was used as the preinoculum, the lesions caused by the virulent isolate A4 were suppressed to about $9 \%$ compared with the control. When Y90-71 (with Avr-Hattan3) was used as the preinoculum, lesions caused by the virulent isolate were suppressed to about $58 \%$ of the control. The lesion index for Y90-71 was significantly higher than that for 3514-R-2 (about 58 versus $9 \%$, respectively). When avirulent isolate A53 (with both AvrPit and AvrHattan3) was used as the preinoculum, the number of lesions was comparable with that when Y90-71 was the preinoculum.

\section{DISCUSSION}

The types of lesion produced by avirulent isolates previously have been considered to depend on the particular combination of resistance genes in the rice and $a v r$ genes in $M$. grisea (14), but this hypothesis had not been confirmed. In the present study, we confirmed this hypothesis using the progeny of isolates representing crosses between parents with different kinds of $a v r$ genes and rice cultivars with different resistance genes. The isolates were previously shown (Table 1) to contain specific $a v r$ genes to the corresponding rice resistance genes.

We demonstrated that the type of resistance lesion depended on the combination of resistance and $a v r$ genes when a single $a v r$ gene-resistance gene pair was present (Fig. 1). The same combination of resistance and $a v r$ genes resulted in a similar type of lesion for any combination of rice cultivar and blast isolate. Furthermore, the resistance response triggered by the presence of both AvrPia and AvrPii in an isolate resulted in lesions similar to those produced by an isolate containing only AvrPia in cultivars carrying both Pia and Pii resistance genes; that is, the rice leaves produced the smaller type of lesion (Fig. 2). A similar result was observed for an isolate containing AvrPit and Avr-Hattan3 (Fig. 3).

Epistatic effects of resistance gene pairs are seen in other plant-pathogen interactions (5). For example, in wheat-stem rust interactions, lower infection types were epistatic to each higher infection types $(22,27)$. Similar reactions were observed in resistance of wheat to the powdery mildew fungus (11). Our results in rice-blast fungus interactions were consistent with those of previous studies.

For bacterial plant pathogens, overlapping and masking effects of $a v r$ genes have been described (12,31). The avrPphC gene of Pseudomonas syringae pv. phaseolicola blocked the avirulence activity of $a v r P p h F$ toward bean cultivar Red Mexican (31). The type III effector AvrRpt 2 from $P$. syringae was found to interfere with AvrBand AvrRpm1-mediated activation of RPM1 in Arabidopsis because AvrRpt2 cleaves RIN4, the target protein of AvrB and AvrRpm1 (12). Similar interactions between $a v r$ and resistance genes might be expected between AvrPii and Avr Pia or AvrPit and Avr-Hattan3 of M. grisea.

We also demonstrated that the degree of leaf blast suppression by preinoculation with an avirulent isolate was determined by the combination of resistance and $a v r$ genes. Iwano (10) preinoculated the avirulent isolate 1, 2, and 3 days before virulent isolate inoculation and compared the de- gree of lesion number suppression. Although Iwano found that the 3-day interval showed the highest suppression of lesion number, we adopted 2 days as the interval in this study because, even at 2 days, the lesion number was suppressed by about $35 \%$ of the control value in Iwano's study.

An avirulent isolate with AvrPii reduced leaf blast more significantly than an isolate with AvrPia (Table 4), and an avirulent isolate with AvrPit suppressed later inoculations with leaf blast more effectively than an isolate with Avr-Hattan3 (Table 4). Avirulent isolates that produced larger resistance lesions tended to suppress leaf blast more effectively than those that produced smaller or invisible lesions (Table 4). Fujita et al. (8) compared the degree of leaf blast suppression by preinoculation with avirulent isolates of various lesion types (no visible symptoms, small brown flecks, and small eyespots with brown margins). They reported that the isolates that produced eyespot lesions with brown margins suppressed later inoculations with virulent isolates most effectively. Ashizawa et al. (3) compared the degree of leaf blast suppression by an avirulent isolate in eight NILs of Sasanishiki rice with different resistance genes. They found that rice lines that produced brown spots in response to preinoculation with an avirulent isolate were more resistant than rice lines that produced no visible symptoms in response to the isolate. Thus, our results are consistent with these previous studies.

We also studied the degree of blast disease reduction by preinoculation with an isolate with two $a v r$ genes. The degree of leaf blast suppression by preinoculation with an isolate containing both AvrPii and AvrPia was not significantly different from that produced by an isolate containing only AvrPia (Table 4). Blast disease reduction by an isolate containing both AvrPit and Avr-Hattan3 was not significantly different from that by an isolate containing only Avr-Hattan3 (Table 4). When two avr genes were involved in determining the avirulence of the isolate, the degree of leaf blast suppression by preinoculation seemed to be comparable with that by preinoculation with an avirulent isolate

Table 4. Effects of preinoculation with an avirulent isolate on the number of lesions produced by inoculation with a virulent isolate (AI3 for Miyamanishiki and A4 for K59)

\begin{tabular}{|c|c|c|c|}
\hline Cultivar, preinoculated isolate ${ }^{y}$ & Avirulence genes & Lesion types (resistance) & Lesion index $(\%)^{\mathrm{z}}$ \\
\hline \multicolumn{4}{|l|}{ Miyamanishiki (Pii, Pia) } \\
\hline Y93-164a-1 & AvrPii & Large brown flecks & $8.8 \pm 5.9 \mathrm{a}$ \\
\hline Y93-165g-1 & AvrPia & Minute brown flecks & $26.3 \pm 8.9 \mathrm{~b}$ \\
\hline $\mathrm{AI} 33$ & AvrPia, AvrPii & Minute brown flecks & $33.6 \pm 15.4 \mathrm{~b}$ \\
\hline \multicolumn{4}{|l|}{ K59 (Pit, Pi-Hattan3) } \\
\hline $3514-\mathrm{R}-2$ & AvrPit & Large brown lesions with a halo & $9.2 \pm 4.9 \mathrm{c}$ \\
\hline Y90-71 & Avr-Hattan3 & No visible lesions & $58.0 \pm 20.2 \mathrm{~d}$ \\
\hline A53 & Avr-Hattan3, AvrPit & No visible lesions & $48.2 \pm 13.2 \mathrm{~d}$ \\
\hline
\end{tabular}

\footnotetext{
${ }^{\mathrm{y}}$ Resistance genes in the cultivar are shown in parentheses.

${ }^{\mathrm{z}}$ Lesion index $(\%)=$ (number of lesions produced by the virulent isolate on a plant preinoculated with the avirulent isolate/number of lesions produced by the virulent isolate on the control seedlings $) \times 100 \%$. Results are means and standard deviations. Statistical analysis was done independently for each cultivar. Thus, values in a column for a given cultivar followed by different letters differ significantly at $P<0.05$ (Tukey-Kramer's test).
} 
with either $a v r$ gene of smaller effect (Table 4). This suggests that, if a cultivar contains two genes resistant to the wild isolates found in an area, the degree of blast disease reduction by infection with avirulent isolates will be similar to that of a cultivar with the resistance gene that produces the smaller effect.

To effectively control rice blast using multilines, it is important to evaluate each NIL for the efficacy of the resistance induced by preinoculation with avirulent isolates. In the present study, we suggested that the combination of resistance genes in the NIL determines the efficacy of resistance induced by avirulent isolates. However, resistance genes of the NILs come from both the shared parent, which is used to introduce resistance genes, and the recurrent parent, which is used to backcross. Therefore, for the effective control of rice blast by multilines, we have to consider not only the introduced resistance genes but also the resistance genes in the recurrent parent cultivar. In Japan, popular rice cultivars such as Sasanishiki, Koshihikari, and Hitomebore, with good eating quality, are used as recurrent parents for many multilines. For example, Sasanishiki contains the blast resistance gene Pia. Consequently, Sasanishiki NIL with $P i i$ has both $P i i$ and Pia. When the avirulent isolate contains both AvrPii and AvrPia, disease reduction by the avirulent isolate infection in a Sasanishiki NIL with Pii will be the same level as that in Sasanishiki. Thus, our results can provide information on the efficacy of using mixtures of NILs for blast control in response to different populations of blast races.

\section{ACKNOWLEDGMENTS}

We thank N. Hayashi of the National Institute of Agrobiological Sciences for kindly providing a fungal strain and S. Koizumi of the National Agricultural Research Center for critical review of an earlier version of this manuscript.

\section{LITERATURE CITED}

1. Abumiya, H. 1955. On the infection types of leaf blast disease of rice plant. Pages 197-201 in: Jubilee Publication in Commemoration of the 60th Birthdays of Prof. Yoshihiko Tochinai and Prof. Teikichi Fukushi. Department of Botany, Faculty of Agriculture, University of Hokkaido, Sapporo, Japan. (In Japanese with English summary)

2. Ashizawa, T., Sasahara, M., Ohba, A., Hori, T., Ishikawa, K., Sasaki, Y., Kuroda, T., Harasawa, R., Zenbayashi-Sawata, K., and Koizumi, S. 2007. Lesion-based analysis of leaf blast suppression in mixture of rice cultivar and a resistant near-isogenic line. J. Gen. Plant Pathol. 73:15-21.

3. Ashizawa, T., Zenbayashi, K., and Sonoda, R. 2005. Effects of preinoculation with an avirulent isolate of Pyricularia grisea on infection and development of leaf blast lesions caused by virulent isolates on near-isogenic lines of Sasanishiki rice. J. Gen. Plant Pathol. 71:345350.

4. Barr, M. E. 1977. Magnaporthe, Telimenella and Hyponectria (Phycosporellaceae). Mycologia 69:952-956.

5. Crute, I. R. 1998. The elucidation and exploitation of gene-for-gene recognition. Plant Pathol. 47:107-113.

6. Ezuka, A., Yuzuki, T., Sakurai, Y., Shinoda, H., and Toriyama, K. 1969. Studies on the varietal resistance to rice blast. 1. Tests for genotype of "true resistance." Bull. Chugoku Natl. Agric. Exp. Stn. E4:1-31. (In Japanese with English summary)

7. Flor, H. H. 1956. The complementary genetic systems in flax and flax rust. Adv. Genet. 8:2954.

8. Fujita, Y., Sonoda, R., and Yaegashi, H. 1990. Blast suppression by pre-inoculation with some incompatible lesion-type isolates of Pyricularia oryzae. Ann. Phytopathol. Soc. Jpn. 56:273-275. (In Japanese with English summary)

9. Hoshi, T., Sasaki, Y., Koide, M., Takeuchi, A., Azuma, S., Sasaki, Y., Yano, K., Hoshino, T., Ichikawa, Y., and Ike, Z. 1992. On the new rice cultivar "YUKINOSEI." Res. Bull. Niigata Agric. Res. Inst. 38:1-14. (In Japanese with English summary)

10. Iwano, M. 1987. Suppression of rice blast infection by incompatible strain of Pyricularia oryzae Cav. Bull. Tohoku Natl. Agric. Exp. Stn. 75:27-39. (In Japanese with English summary)

11. Jørgensen, J. H., and Jensen, C. J. 1972. Genes for resistance to wheat powdery mildew in derivatives of Triticum timopheevi and T. carthlicum. Euphytica 21:121-128.

12. Kim, H.-S., Desveaux, D., Singer, A. U., Patel, Sondek, J., and Dangl, J. L. 2005. The Pseudomonas syringae effector AvrRpt 2 cleaves its C-terminally acylated target, RIN4, from Arabidopsis membranes to block RPM1 activation. Proc. Natl. Acad. Sci. USA 102:64966501.

13. Kiyosawa, S. 1968. Genetic relationship among blast resistance and other characters in hybrid of Korean variety, Doazi chall (Butamochi), with Aichi Asahi. Jpn. J. Breed. 18:8893.

14. Kiyosawa, S. 1970. Typical reaction of differential rice cultivars to Pyricularia oryzae. (In Japanese) J. Agric. Sci. 5:578-580.

15. Kiyosawa, S. 1972. The inheritance of blast resistance transferred from some indica varieties of rice. Bull. Natl. Inst. Agric. Sci. D23:69-96.

16. Kiyosawa, S. 1974. Inheritance of blast resistance in rice cultivar Hokuriku 12. Agric. Hortic. 49:1030-1040. (In Japanese)

17. Kiyosawa, S. 1984. Establishment of differential varieties for pathogenicity test of rice blast fungus. Rice Genet. Newslett. 1:95-97.

18. Kiyosawa, S., Inoue, M., and Matsumoto, N., 1978. Concept of classification of blast resistance of rice. Plant Prot. 32:455-461. (In Japanese)

19. Koizumi, S. 2001. Rice blast control with multilines in Japan. Pages 143-157 in: Exploiting Biodiversity for Sustainable Pest Management. International Rice Research Institute, Los Baños, The Philippines.

20. Koizumi, S., Ashizawa, T., and Zenbayashi, K. 2004. Durable control of rice blast disease with multilines. Pages 191-199 in: Rice Blast: Interaction with Rice and Control. Kluwer Academic Publishers, Dordrecht, The Netherlands.

21. Koumura, T., Takamatsu, M., Shaku, I., Shumiya, A., Haga, K., Taniguchi, M., Kudou, S., Ito, K., Tanabe, K., Nakazima, Y., and Kutsuna, Y. 1983. A new rice variety 'Megumimochi'. Res. Bull. Aichi Agric. Res. Cent.
15:14-23. (In Japanese with English summary)

22. Loegering, W. Q., and Powers, H. R., Jr. 1962. Inheritance of pathogenicity in a cross of physiological races 111 and 36 of Puccinia graminis f. sp. tritici. Phytopathology 52:547554.

23. Manandhar, H. K., Lyngs Jørgensen, H. J., Mathur, S. B., and Smedegaard-Petersen, V. 1998. Suppression of rice blast by preinoculation with avirulent Pyricularia oryzae and the nonrice pathogen Bipolaris sorokiniana. Phytopathology 88:735-739.

24. Morimoto, T., Ito, T., Tanabe, K., Nakamori, M., Taniguchi, M., Inagaki, A., Inoue, M., Asai, Y., Ito, Y., Shumiya, A., and Fujii, K. 1980. A new rice variety 'Mineasahi.' Res. Bull. Aichi Agric. Res. Cent. 12:24-36. (In Japanese with English summary)

25. Morimoto, T., Tanabe, K., Ito, T., Inoue, M., Ito, Y., Shumiya, A., Inagaki, A., Asai, Y., and Fujii, K. 1981. A new rice variety 'Horei.' Res. Bull. Aichi Agric. Res. Cent. 13:1-13. (In Japanese with English summary)

26. Ohata, K., and Kozaka, T. 1967. Interaction between two races of Pyricularia oryzae in lesion formation in rice plants and accumulation of fluorescent compounds associated with infection. Bull. Natl. Inst. Agric. Sci. C21:111135. (In Japanese with English summary)

27. Roelfs, A. P. 1988. Genetic control of phenotypes in wheat stem rust. Annu. Rev. Phytopathol. 26:351-67.

28. Rossman, A. Y., Howard, R. J., and Valent, B. 1990. Pyricularia grisea, the correct name for the rice blast fungus. Mycologia 82:509-512.

29. Shimoyama, M., Endo, T., Kondo, M., and Kurahasi, Y. 1965. Classification of blast resistance in rice cultivars popular in Kanto Tokai Hokuriku district by various blast isolates. Proc. Assoc. Plant Prot. Hokuriku 13:34-36. (In Japanese)

30. Silue, D., Notteghem, J. L., and Tharreau, D. 1992. Evidence of a gene-for-gene relationship in the Oryza sativa-Magnaporthe grisea pathosystem. Phytopathology 82:577-580.

31. Tsiamis, G., Mansfield, J. W., Hockenhull R., Jackson, R. W., Sesma, A., Athanassopoulos, E., Bennet, M. A., Stevens C., Vivian, A., Taylor, J. D., and Murillo, J. 2000 Cultivar-specific avirulence and virulence functions assigned to avrPphF in Pseudomonas syringae pv. phaseolicola, the cause of bean halo-blight disease. EMBO J. 19:3204-3214.

32. Yaegashi, H., Asaga, K., and Yamada, M. 1983. Presumed genotypes for true resistance of recommended rice varieties to rice blast. Bull. Tohoku Natl. Agric. Exp. Stn. 68:1-19. (In Japanese with English summary)

33. Yamada, M., Matsumoto, S., and Kousaka, T. 1969. Grouping of Japanese rice varieties on the basis of the reactions to pathogenic races of Piricularia oryzae Cav. Bull. Natl. Inst. Agric. Sci. C23:37-62. (In Japanese with English summary)

34. Yamasaki, Y., and Kiyosawa, S. 1966. Studies on inheritance of resistance of rice varieties to blast. 1. Inheritance of resistance of Japanese varieties to several strains of the fungus. Bull. Natl. Inst. Agric. Sci. D14:39-69. (In Japanese with English summary)

35. Yasuda, N., Fujita, Y., and Noguchi, M. 2004. Identification of avirulence genes in the rice blast fungus corresponding to three resistance genes in Japanese differentials. J. Gen. Plant Pathol. 70:202-206.

36. Yasuda, N., Noguchi, M. T., and Fujita, Y. 2005. Identification of an avirulence gene in the fungus Magnaporthe grisea corresponding to a resistance gene at the Pik locus. Phytopathology 95:768-772. 